Fäulniss befördern, ohne dabei auch nur eine theilweise Zersetzung zu erfahren, so erhält dadurch die Liebig'sche Fäulnisstheorie einen neuen Stoss, denn wie die anderen genau definirten Gährungsarten, so wird dann auch die Fäulniss eine correlative Erscheinung des Lebens und nicht des Todes. (Journ. de Pharm. et de Chimie. 4. Serie. Tom. $X I X$. 257 u. 354.).

Dr. G. $V$.

\title{
Analytischer Nachweis des Anilins in Gemengen.
}

E. Jacquemin hat, obgleich Vergiftungen mit reinem Anilin oder dessen Salzen bisher noch nicht vorgekommen sind, sich doch in der Voraussicht, dass ein derartiger Nachweis einmal von einem Gerichtschemiker verlangt werden könnte, mit Aufsuchung der Mlethode beschäftigt, welche in diesem Falle am Leichtesten und Sichersten zum Ziele führen würde und bezeichnet als solche das folgende Verfahren.

Von der verdächtigen Substanz, sei es Blut, Fleisch oder ein anderes organisches Gewebe, werden $100 \mathrm{~g}$. in der geeigneten Form erst mit 100 und dann ein zweites Mal mit $50 \mathrm{~g}$. destillirtem Wasser, welches 2 Procent Schwefelsäure enthält, durch mehrstündige Digestion bei $40^{\circ}$ erschöpft und ausgepresst. Die so erhaltene Flüssigkeit dunstet man bei ziemlich niederer Temperatur bis zur Syrupsconsistenz ein, setzt das vierfache Volum Alkohol $\mathrm{zu}$, filtrirt, behandelt das Filtrat mit einer Löвung von kohlensaurem Kali, setzt Aether zu und schüttelt damit. Die ätherische Schicht wird decantirt und aus ihr durch eine ätherische Oxalsäurelösung das Anilin als oxalsaures Salz gefällt, welches in Aether ganz unlöslich ist und daher durch Waschen mit solchem vollkommen rein erhalten werden kann. Durch kohlensaures Kali wird das Anilin wieder in Freiheit gesetzt, in Aether aufgenommen und verbleibt bei dessen Verdunsten im reinen Zustande, so dass dann die verschiedenen bekannten characteristischen Farbenreactionen damit vorgenommen werden können, von welchen Jacquemin besonders die mit unterchlorigsaurem Natron als sehr.empfindlich hervorhebt.

Weil jedoch in der durch Digestion mit saurem Was. ser erschöpften Substanz noch Anilide enthalten sein können, so wird diese mit sehr verdünnter Schwefelsäure in einer Retorte längere Zeit gekocht, wobei die Anilide, analog den Amiden, zersetzt werden, indem sich Anilinsulfat bildet. Die 
so gewonnene Flässigkeit wird dann in gleicher Weise wie die erste weiter behandelt. (Journ. de Pharm. et de Chim. 4. Serie. Tom. XIX. pag. 341.). Dr. G. V.

\section{Die Pyrogallussäure als Reagens.}

Das Verhalten der Pyrogallussäure zu den Alkalien und alkalischen Erden ist hinlänglich bekannt; sie bildet mit den ätzenden Alkalien dunkelbraune Verbindungen, und mit Kalkwasser eine schöne violette Flüssigkeit, und zuletzt setzt sich daraus ein schwarzer Körper $a b$, dessen Natur noch nicht erforscht ist. Die einfachen und $\mathrm{Bi}$-Carbonate liefern ähnliche Resultate. Auf Zusatz weniger Tropfen einer 10procentigen Pyrogallussäure-Lösung zu einer Lösung von doppelt-kohlensaurer Magnesia oder doppelt-kohlensaurem Kalk entsteht anfangs keine Färbung, aber nach sechs Stunden findet man einen reichlichen schwarzen Niederschlag abgelagert. Von dieser Reaction macht Schlagdenhauffen Gebrauch bei der Untersuchung alkalischer Mineralwässer; in solchen, welche viel Carbonat enthalten, entsteht nemlich sogleich, eine gelbe Färbung, und nach 10 bis 12 Stunden hat sich ein beträchtlicher schwarzer Präcipitat gebildet, während bei $\mathrm{Ab}$ wesenheit löslicher Carbonate nichts derartiges oder höchstens eine gelbliche oder blassbräunliche Färbung eintritt. Kalkcarbonat lässt sich schon in wenig CC. Trinkwasser auf Zusatz einiger Tropfen Pyrogallussäure-Lösung nachweisen.

Auch die Alkaloïde geben mit der Pyrogallussäure braune oder doch wenigstens orangegelbe Färbungen, aber erst nach längerem, etwa zwölfstündigem Stehen. Dieses Verhalten unterscheidet dieselben übrigens von den neutralen krystallinischen Körpern und den Glykosiden, denn diese verhalten sich gegen jene Säure völlig indifferent. In der Wärme nehmen jene Färbungen an Tiefe zu. Setzt man zu einer solchen gefärbten Flüssigkeit eine weingeistige Iüsung von Qnecksilberchlorid, so entsteht gleich ein schwarzer Niederschlag, während Pyrogallussäure-Lösung, welche ein Glykosid oder einen neutralen krystallinischen Körper enthält, durch Quecksilberchlorid keine Veränderung erleidet.

Es wurden einige auf die vorstehende Reaction basirte Versuche angestellt, um die relative Alkalinität der Alkalö̈de za ermitteln. $\mathrm{Zu}$ diesem Zwecke löste man $1 \mathrm{~g}$. Pyrogallussäure in $10 \mathrm{CC}$. Weingeist, setzte dazu $2 \mathrm{CC}$. einer gesättig- 